\title{
Saúde Ocupacional na região central do estado de Nova York: um ambulatório de doenças ocupacionais com financiamento público 25 anos depois
}

\author{
Occupational Health in central New York: a publicly funded \\ occupational health clinical center after 25 years
}

\begin{abstract}
1 Occupational Health Clinical Centers. Department of Family Medicine, State University of New York Upstate Medical University, Syracuse, NY, USA.
\end{abstract}

Contato:

Email:

laxm@upstate.edu

Tradução

Lucas Ferreira de Campos

Carlos Eduardo Siqueira

Revisão final da tradução

Kleber dos Santos

O autor declara que não há conflito de interesse.

\section{Resumo}

Para tratar o problema do sub-reconhecimento de agravos relacionados ao trabalho, em 1987, o estado de Nova York utilizou financiamentos públicos para criar uma rede de ambulatórios de saúde ocupacional, que continua sendo o único projeto de seu tipo nos Estados Unidos. Sua missão é o diagnóstico, o tratamento e a prevenção de doenças ocupacionais. O financiamento público foi necessário para sustentá-la e permitir que funcionasse de forma independente e universalmente acessível. Este artigo relata as experiências dos Ambulatórios de Saúde Ocupacional (Occupational Health Clinical Centers - OHCC) ao longo dos últimos 25 anos. Cada serviço é parte da rede e atende grande parte da região central do estado de Nova York. Durante este período, os ambulatórios construíram uma experiente equipe multidisciplinar e um programa multifacetado, que inclui atividades clínicas, ações de capacitação e educação, assessoria técnica e pesquisa. Alcançaram considerável sucesso em estabelecer-se como um recurso para os trabalhadores acidentados na região e como defensores, do ponto de vista clínico, de trabalhadores acidentados nos seus locais de trabalho e junto ao sistema de compensação. Como os OHCCs se movem em direção à nova fase, desafios consideráveis permanecem, especialmente na identificação e no acesso de trabalhadores submetidos a situações de alto risco com pouco alcance aos serviços de saúde.

Palavras-chave: ambulatório de saúde ocupacional; saúde do trabalhador; medicina do trabalho; serviços de saúde ocupacional; disparidades em saúde ocupacional.

\begin{abstract}
To address the problem of the under-recognition of occupational disease, New York State used public funds to create a network of occupational health clinical centers (OHCN) in 1987. New York State's OHCN remains the only project of its kind in the United States. The mission of the network centers was the diagnosis, treatment and prevention of occupational illness. Public funding was necessary to sustain the network and to allow it to function independently and to be universally accessible. This paper reports on the experiences of the Occupational Health Clinical Centers (OHCC) over the last 25 years. The OHCC is part of the OHCN serving a large portion of central New York State. Over this time period the OHCC has built an experienced multidisciplinary team and a multi faceted program including clinical activities, training and education, technical assistance, and research. The OHCC has achieved considerable success in establishing itself as a resource for injured workers in the region, and as an advocate for injured workers medically, in their workplaces, and in the Workers' Compensation system. As the OHCC moves into its next phase, considerable challenges remain, particularly in identifying and reaching high risk and under-served workers.
\end{abstract}

Keywords: occupational health clinics; worker health; occupational medicine; occupational health services; disparities in occupational health. 


\section{Origens e missão da rede de clínicas de Saúde Ocupacional $(\mathrm{OHCN})^{2}$}

Em meados dos anos 1980, ficou evidente para sindicatos, ativistas de saúde e segurança no trabalho, acadêmicos e profissionais interessados em saúde do trabalhador que a questão das doenças ocupacionais era um problema sem a devida atenção no estado de Nova York. Para remediar a situação, foi projetada uma rede de ambulatórios especializados em saúde ocupacional que cobrisse o estado. O Comitê de Segurança e Saúde Ocupacional de Nova York, uma coalizão de sindicatos, profissionais da saúde e segurança no trabalho e ativistas iniciaram uma campanha para obter financiamento para uma rede de ambulatórios.

Havia duas chaves para o sucesso da campanha. A primeira seria a construção de uma aliança no âmbito estadual que fosse capaz de atingir políticos, tanto democratas, quanto republicanos. Democratas representavam a maioria dos centros urbanos, incluindo Nova York, enquanto Republicanos dominavam as áreas rurais e suburbanas do norte do estado e em Long Island. O segundo elemento-chave foi um estudo acadêmico acerca da doença ocupacional no estado de Nova York, realizado por pesquisadores da Universidade Mount Sinai (doravante indicado como "estudo da Mount Sinai"), em Nova York, usando financiamentos que haviam sido obtidos do Estado.

O estudo da Mount Sinai (LANDRIGAN; MARKOWITZ, 1987) documentou e quantificou o que os sindicatos e ativistas haviam argumentado há muito tempo, mostrando que: 1) Um número significativo de trabalhadores morreu ou adoeceu como resultado de exposições no local de trabalho a cada ano em Nova York; 2) Muitos trabalhadores em todo o estado trabalhavam em condições perigosas, colocando-os em risco de desenvolver doenças ocupacionais; 3) Os custos econômicos por doença ocupacional eram enormes; 4) Havia uma ausência quase total de serviços médicos ocupacionais em todo o estado para lidar com estes problemas. Como solução para o problema, o estudo da Mount Sinai imaginou uma rede de ambulatórios de saúde ocupacional $(\mathrm{OHCC})^{3}$ que seria financiada pelo Estado para diagnosticar, tratar e prevenir doenças ocupacionais. Cada centro teria responsabilidade regional, tornando possível o acesso em todo o estado, e seria composto por uma equipe multidisciplinar li- derada por um médico especializado em medicina do trabalho. O núcleo da equipe deveria conter um higienista industrial e um assistente social.

O financiamento público da rede foi necessário para a construção de organizações que não seriam viáveis enquanto empresas privadas. Além disso, permitiu aos ambulatórios ficarem livres da dependência financeira direta dos empregadores, assegurando, desta forma, opiniões independentes. Outro benefício crucial do financiamento público foi a acessibilidade universal das clínicas. Qualquer trabalhador, possuindo ou não seguro de saúde ou meios de pagamento, poderia utilizar os serviços da clínica.

Um último aspecto fundamental da visão proposta pelo estudo da Mount Sinai foi a exigência de que cada serviço recrutaria e manteria um Conselho Comunitário Consultivo, que funcionaria como conexão entre os serviços e as comunidades, transmitindo as necessidades da comunidade para a clínica e assegurando que as clínicas atendessem essas necessidades. Os conselhos também serviriam como importantes voluntários que sensibilizariam a comunidade sobre as clínicas.

Depois que o estudo da Mount Sinai foi divulgado, a coalizão estadual usou-o como ferramenta para tentar convencer os legisladores do Estado sobre a necessidade de financiamento contínuo no projeto de rede. Inteligentemente, o estudo continha elementos e recomendações destinadas a uma ampla gama de legisladores. A maioria destes poderia encontrar algo desejável nas clínicas que ofereceriam cuidados de alta qualidade e seriam acessíveis, atendendo às necessidades de um público amplo. A confederação sindical AFL-CIO (American Federation of Labor - Congress of Industrial Organizations ${ }^{4}$ ) era um membro da coalizão e assumiu essa questão com alta prioridade. A influência de trabalhadores foi outra importante razão para os políticos apoiarem a criação da rede (TUMINARO, 1990).

Em 1987, a Assembleia Legislativa do estado criou a Rede de Ambulatórios de Saúde Ocupacional (OHCN). O financiamento viria de pequeno aumento no valor cobrado nos prêmios dos seguros de compensação ${ }^{5}$ dos trabalhadores, os quais, em teoricamente, todos os empregadores são obrigados a contratar. O valor total do financiamento para a rede seria determinado anualmente pelo governador e pelo Poder Legislativo, junto com o restante do orçamento do

\footnotetext{
${ }^{2}$ N.T.: Occupational Health Clinic Network (OHCN). Manteremos ao longo do texto a sigla em inglês.

${ }^{3}$ N.T.: Occupational Health Clinical Centers (OHCC). Manteremos ao longo do texto a sigla em inglês.

${ }^{4}$ N.T.: Trata-se da maior central sindical dos Estados Unidos (http://www.aflcio.org) - Fonte: Wikipedia. Disponível em: < http://en.wikipedia. org/wiki/AFL\%E2\%80\%93CIO >. Acesso em: 10 jun. 2013.

${ }^{5}$ N.T.: Seguros de compensação: a compensação dos trabalhadores (workers' compensation) é um sistema estatal que prevê o pagamento de serviços médicos, compensação parcial dos salários perdidos e reabilitação profissional para trabalhadores lesionados.
} 
Estado. O valor legislado seria administrado pelo State Department of Health ${ }^{6}(\mathrm{DOH})$, que havia lançado edital para propostas de subvenção com a intenção de financiar um ambulatório em cada região designada do estado, com exceção da cidade de Nova York, onde haveria dois. Inicialmente, sete ambulatórios foram financiados, cada um com sua própria base institucional. Cinco foram estabelecidos em faculdades de medicina e outros dois de forma independente. Um oitavo ambulatório específico logo foi acrescentado, com um mandato para se concentrar com exclusividade sobre os riscos agrícolas em todo o estado.

A cada cinco anos, o estado lança novo edital para propostas de subvenção. Em 2008, a configuração regional foi alterada com a adição de três novas regiões. Ao invés de criar novos ambulatórios para as novas regiões, os ambulatórios existentes aumentaram sua cobertura.

\section{Origens e desenvolvimento do ambula- tório de Syracuse}

Syracuse foi o local escolhido para o ambulatório que serviria a região central do estado de Nova York. Esta região abrangia uma grande área, cobrindo mais de 200 milhas de norte a sul e mais de 100 milhas* de leste a oeste. Syracuse e seus arredores, com uma população de aproximadamente 450.000 habitantes, era o maior centro urbano na região. Como grande parte do nordeste dos Estados Unidos, Syracuse e o centro do estado de Nova York tinham uma economia baseada na produção manufatureira, em transição na década de 1980. Ao longo dos anos, grande parte da base industrial fechou, deixando a educação, a saúde e outros serviços como empregadores dominantes.

É preciso também mencionar que a população de Syracuse era multiétnica, com comunidades afro-americanas estabelecidas há muito tempo. Comunidades latinas de várias origens (predominantemente de Porto Rico, República Dominicana e Cuba, com um menor número de mexicanos, guatemaltecos e outros países da América Central e do Sul) cresceram de forma significativa. Além disso, grupos de imigrantes da Ásia (Vietnã, Laos), da África (Sudão, Somália) e da Europa Oriental (Bósnia) foram adicionados à população. Em contraste, a área rural e as pequenas cidades da região permaneceram predominantemente brancas, embora em algumas áreas os trabalhadores migrantes (em especial do México e da Guatemala) tenham presença significativa.
A presença de sindicatos na região central do estado de Nova York diminuiu acentuadamente desde a abertura do primeiro OHCC. Mais de $25 \%$ da força de trabalho do estado era sindicalizada no final de 1980. Como em grande parte do resto dos Estados Unidos, os sindicatos industriais perderam uma parcela desproporcional de membros com a saída da indústria da região. Os metalúrgicos mantêm presença forte na região, assim como sindicatos representando trabalhadores da saúde, da educação e do setor público.

Desde sua criação, o OHCC Syracuse tem sido sediado na State University of New York Upstate Medical (SUNYUM) ${ }^{7}$. É um programa do Departamento de Medicina da Família.

Em 2008, a área servida pelo OHCC foi substancialmente ampliada e dividida em três regiões separadas após reorganização conduzida pelo $\mathrm{DOH}$. Embora as regiões sejam distintas, todas foram integradas em um único sistema de OHCC. Centros regionais foram desenvolvidos em Canton, 125 milhas ao norte de Syracuse, e em Binghamton, 75 milhas** ao sul de Syracuse. Os escritórios regionais são formados por uma combinação de moradores locais e residentes em Syracuse. Os OHCC são administrados por uma equipe de Syracuse e cada região tem seu próprio Conselho Consultivo.

\section{Equipe clínica}

A equipe do OHCC foi concebida de forma multidisciplinar, treinada em saúde ocupacional, e liderada por um médico atuando como diretor médico. $\mathrm{O}$ DOH exigiu que o diretor tivesse residência médica e fosse diplomado em medicina do trabalho. Um administrador, um higienista industrial e um assistente social completaram a equipe profissional.

O OHCC começou com um diretor médico e um administrador, em conjunto com um assistente de consultório médico (ACM) e secretário. O papel do ACM seria: o contato direto multifacetado e inclusivo com o paciente; a organização e a gestão de acompanhamento médico; e a cobrança. Rapidamente se tornou evidente que as funções desempenhadas pelo ACM seriam demasiadamente exaustivas para serem executadas por uma única pessoa e por isso um responsável pela cobrança foi logo contratado. Ao longo dos dois anos seguintes, um higienista industrial e um assistente social foram recrutados. Além disso, uma enfermeira com vasta experiência foi adicionada à equipe, de início para fornecer assistência direta ao paciente. Mais tarde, seu papel foi expandido

\footnotetext{
${ }^{6}$ N.T.: Departamento estadual de saúde. No Brasil, o termo indicado seria "secretaria”.

${ }^{7}$ N.T.: Universidade Médica Estadual do Norte de Nova York.

*Equivalentes a 321 quilômetros e 160 quilômetros, respectivamente.

粎 Equivalentes a 200 quilômetros e 120 quilômetros, respectivamente.
} 
para diretora de serviços ambulatoriais, assumindo responsabilidades de supervisão e administração.

Ao longo dos anos subsequentes, a equipe cresceu significativamente. No aspecto clínico, novos profissionais foram adicionados para lidar com o aumento da carga de pacientes. Por alguns anos, um segundo médico de medicina do trabalho foi empregado. No entanto, as restrições financeiras impediram o OHCC de manter este médico. Quando as operações do OHCC expandiram-se regionalmente, contou-se com enfermeiras especializadas para trabalharem nos escritórios regionais e reforçar o ambulatório de Syracuse. Atualmente existem quatro enfermeiras que trabalham em colaboração com o diretor médico.

Os pacientes são compartilhados por todos os profissionais em qualquer consultório. Esta estruturação permitiu ao OHCC maximizar a quantidade de atendimentos ao paciente, apesar das restrições financeiras. Esta decisão também criou dois problemas específicos. O primeiro é que as enfermeiras são treinadas em cuidados de adultos ou de família e não recebem formação específica em medicina do trabalho. A curva de aprendizagem, consequentemente, pode ser muito prolongada, o que exige treinamento significativo e apoio contínuo. O segundo problema diz respeito ao Seguro de Compensação dos Trabalhadores. Defender os direitos dos pacientes cobertos por esse sistema é uma função crucial e importante do OHCC. Este seguro é mais atrasado do que outros sistemas de seguro e não reconhece comentários ou opiniões de outros profissionais que não sejam médicos. Consequentemente, é necessária uma programação cuidadosa dos pacientes para garantir que o diretor médico os atenda com certa regularidade. Além disso, outras medidas foram tomadas para garantir ao Conselho de Compensação dos Trabalhadores e às seguradoras que as enfermeiras são supervisionadas pelo diretor médico e que todas as decisões relativas à causalidade, ao diagnóstico, ao tratamento de doenças e à incapacidade estão sendo tomadas por ele ou têm, ao menos, seu consentimento. Estas exigências feitas pelo Conselho de Compensação dos Trabalhadores contradizem as regulamentações nacionais e do Estado, que caracterizam a relação entre o diretor médico e as enfermeiras como colaborativa e concedem às enfermeiras uma ampla gama de práticas que o sistema de compensação de trabalhadores proíbe.

Com o tempo, tornou-se claro que o desenho inicial da composição da equipe não atenderia adequadamente às necessidades de acompanhamento dos casos em avaliação na compensação de trabalhadores. Além das necessidades diárias de organizar testes de diagnóstico, gerenciar encaminhamentos, acompanhar resultados de testes e referências, atender a perguntas de pacientes, entre outras exigências, a compensação de trabalhadores impõe um grande conjunto de regras e requisitos adicionais. Como consequência, o trabalho de acompanhamento dos casos multiplicou-se absurdamente, sendo que seu escopo de fato não se encontrava nos planos iniciais da equipe. O OHCC hoje emprega quatro enfermeiras gerentes de casos para atender tais necessidades. As enfermeiras gerentes de casos também prestam cuidados diretos ao paciente, verificam sinais vitais, realizam exames e coletam sangue.

Outra necessidade de pessoal que merece ser mencionada é a de atividades externas e educação. Era evidente desde o início que os esforços de expansão das ações para fora da clínica seriam essenciais para aumentar o conhecimento sobre o OHCC e o desenvolvimento de relações com outras organizações da região. Inicialmente, essas atividades foram realizadas através de contratos com organizações comunitárias. Estas relações se mostraram valiosas, mas foi difícil manter a constante comunicação necessária para maximizar a colaboração e a efetividade. Mais recentemente, um financiamento suficiente foi conseguido para contratar uma pessoa responsável por estas ações em tempo integral para o escritório de Syracuse e outra em meio período para os escritórios regionais. Isso resultou em uma melhora significativa na natureza e na qualidade dos esforços de expansão externa, uma vez que os funcionários que desempenham esta atividade estão totalmente integrados à equipe multidisciplinar do OHCC. O centro mantém contratos de serviços com dois Centros de Trabalhadores, mas estas parcerias são organizadas e supervisionadas de perto pela equipe contratada do OHCC.

Atualmente, o OHCC está em transição dos prontuários médicos de papel para eletrônicos. Prevê-se que esta medida irá alterar de forma significativa tanto a natureza, quanto a quantidade de trabalho relacionado aos pacientes. Como resultado, as responsabilidades da equipe e talvez a composição dos membros da equipe mudem.

\section{Atividades clínicas}

\section{Assistência ao paciente}

Avaliar indivíduos com suspeita de doença ocupacional é a atividade principal do OHCC. Cerca de 6.000 pacientes foram observados por meio de aproximadamente 25.000 visitas desde que as portas se abriram em 1989. A maioria vem para a clínica solicitando parecer sobre a relação do trabalho com sua condição de saúde. Percentagem muito pequena (menos de 5\%) procura avaliação por doença ou sintomas possivelmente não relacionados ao trabalho (exposições domésticas ou outras). 
No início, esperava-se que os pacientes fossem vistos uma ou duas vezes, um parecer seria emitido sobre o nexo causal e a incapacidade do paciente, que então seria encaminhado ao seu clínico para a continuidade do tratamento. Observa-se que esta não é a realidade da maioria dos pacientes que são acompanhados por períodos prolongados e recebem tratamento no OHCC. A principal razão para isso é que muitos médicos hesitam em aceitar pacientes com doenças relacionadas ao trabalho, principalmente porque não querem participar do sistema de compensação dos trabalhadores.

Pacientes com lesões e doenças relacionadas ao trabalho têm direito a benefícios do sistema de compensação de trabalhadores. Em tese, médicos são legalmente obrigados a cobrar desse seguro por todos os pacientes que atendem com doenças ou acidentes relacionados ao trabalho. A compensação de trabalhadores é um sistema estatal que prevê o pagamento de serviços médicos, a compensação parcial dos salários perdidos e a reabilitação profissional para trabalhadores lesionados. Os empregadores compram o seguro de acidentes de trabalho de empresas de seguros. Consequentemente, os Estados Unidos têm um sistema duplo de prestação de cuidados de saúde: um para problemas médicos não relacionados ao trabalho e outro para doenças e acidentes relacionados ao trabalho.

Trabalhadores acidentados, no entanto, ficam frequentemente presos no meio dos dois sistemas, quando seus casos são contestados pelos agentes das seguradoras. Os testes de diagnóstico e de tratamento para trabalhadores acidentados são com frequência adiados pelas operadoras de seguros e estes atrasos podem durar meses ou até um ano ou mais antes que os problemas sejam resolvidos. Nesse ínterim, o paciente não pode utilizar seu seguro de saúde, mesmo que ele o possua. Estes atrasos, além do tratamento burocrático, das dificuldades para receber e da necessidade de depoimentos, estão entre as razões pelas quais os médicos interessam-se cada vez menos em participar do sistema de compensação de trabalhadores. Reformas legislativas recentes tornaram a situação ainda pior.

Neste contexto, o OHCC tem lutado para manter seu foco clínico em pacientes com doença ocupacional. Por muitos anos, a distribuição de diagnósticos dos pacientes atendidos no OHCC foi composta de cerca de $30 \%$ a $40 \%$ de doenças respiratórias e 30\% de lesões musculoesqueléticas em braços, ombros e pescoço devido a esforços repetitivos e crônicos. O restante inclui uma variedade de problemas de saúde decorrentes de exposição a químicos, metais, pesticidas ou ruído. Mais recentemente, o perfil de pacientes passou a incluir muitas pessoas que procuram tratamentos continuados e ajuda para suas solicitações de compensação por dores crônicas depois de lesões agudas, na sua maioria na região lombar.
Quase metade dos pacientes atendidos trabalha em setores tradicionalmente considerados perigosos: construção civil, mineração e indústria manufatureira. Um terço trabalha na administração pública (incluindo polícia, bombeiros e guardas penitenciários), na educação e nos cuidados de saúde. Os principais tipos de exposições perigosas associadas a doenças ou lesões entre os pacientes do OHCC incluem fatores ergonômicos (por exemplo, movimentos repetitivos, posturas extremas, atividades que exigem muita força), asbestos e trauma agudo. Outras exposições são variadas sem qualquer predominância específica. Poluição do ar em ambientes fechados, que inclui bioaerossóis, produtos de limpeza, solventes, ruídos e exposição a contaminantes presentes no World Trade Center, após o 11 de setembro, têm sido relativamente comuns. Exposições ao chumbo e a outros metais, assim como a pesticidas, foram informados com frequência muito menor (OCCUPATIONAL HEALTH CLINICAL CENTERS, 2010).

\section{O papel do assistente social}

$\mathrm{O}$ assistente social tem sido um membro central da equipe do OHCC desde o início do ambulatório. Essa necessidade é baseada no reconhecimento de que o diagnóstico de uma doença ocupacional tem, com frequência, significativas consequências psicológicas, sociais e financeiras. Trabalhadores acidentados muitas vezes perdem seus empregos e, consequentemente, seus salários e benefícios (dentre eles, o seguro de saúde), o que resulta em graves prejuízos financeiros que podem nunca ser ressarcidos. Além disso, trabalhadores lesionados que perdem seus empregos também perdem muitas amizades e conexões sociais e de apoio, assim como sofrem um sério golpe em sua autoidentidade. Depressão, raiva e ansiedade são quase certas, e geralmente se tornam incapacitados perante si próprios e os outros.

O assistente social do OHCC aborda estas questões de várias maneiras. Os pacientes são encaminhados tanto pelos médicos que identificaram problemas que precisam de atenção do assistente social, quanto por solicitação do próprio paciente. O paciente é avaliado e serviços adequados são oferecidos. Normalmente incluem: aconselhamento de curto prazo para ansiedade, depressão ou outros problemas emocionais; encaminhamento aos recursos comunitários para saúde mental caso o paciente necessite de psicoterapia de longo prazo e/ou medicação; facilidade de acesso a outros benefícios. Estes, mais comumente, englobam, em curto prazo, o seguro social para incapacidade, o seguro de saúde oferecido ou subsidiado pelo Estado, vale-refeição e acesso à habitação e transporte subsidiados. 
Trabalhadores lesionados também têm participado em sessões de grupos organizadas pelo assistente social, que incluem grupos de apoio por tempo limitado e grupos educacionais. Os grupos de apoio focam, por vezes, em trabalhadores com alguns tipos específicos de problema de saúde, como distúrbios osteomusculares e múltiplas sensibilidades químicas. Grupos educacionais trouxeram palestrantes para abordar questões que membros do grupo identificaram como problemas, tais como o sistema de compensação de trabalhadores ou o modo como condições específicas são diagnosticadas e tratadas clinicamente.

\section{Prevenção de doença ocupacional}

Embora o diagnóstico e o tratamento de doenças e lesões sejam a prioridade das atividades do OHCC, a prevenção continua a ser o objetivo central, talvez elusivo. Muitos dos esforços de prevenção do OHCC começam com um só paciente e incluem a participação do higienista do OHCC, que é um membro central da equipe. Em reuniões semanais com pacientes, a situação de cada um é avaliada a fim de determinar se são necessárias ou recomendadas medidas de controle de exposição no local de trabalho para manter o paciente na sua atividade laboral ou para retornar ao trabalho. Uma estratégia é desenvolvida junto com o paciente para tentar persuadir o empregador a aceitar as alterações recomendadas. A responsabilidade do higienista inclui: coleta e análise de dados de exposição; recomendações para coleta de dados posteriores, englobando investigação no local de trabalho; e recomendações para alterações no local de trabalho a fim de controlar os problemas de exposição identificados.

Uma das principais barreiras enfrentadas pelo higienista é que o acesso do OHCC aos locais de trabalho dos pacientes é bastante limitado. O OHCC não tem poder de fiscalização e precisa ser convidado pelo empregador ou o sindicato (se houver) para ir até o local de trabalho.

Apesar dos serviços gratuitos ou de baixo custo do OHCC e de seu papel não governamental que oferece conhecimentos e experiência sem a ameaça de multas, os empregadores raramente optam por utilizar os serviços do higienista industrial do OHCC. Isto se dá provavelmente porque o centro é visto como bastante alinhado com o trabalhador acidentado e com frequência apoia reivindicações de compensação de trabalhadores contra as empresas.

Os sindicatos têm o direito de trazer seu próprio perito para avaliar a saúde e a segurança no local de trabalho, mas o fazem apenas ocasionalmente. Em resposta a uma recomendação do OHCC para uma avaliação do local de trabalho, os empregadores con- tratam seu próprio consultor de higiene industrial. Se um sindicato está envolvido, ele pode inicialmente fazer pressão para o OHCC também participar, mas muitas vezes negociam a contratação de outro consultor aceitável para a empresa ao invés de insistir no OHCC como seu especialista escolhido. Como consequência, o centro raramente tem acesso direto ao local de trabalho e o higienista do OHCC encontra-se, em geral, na posição de crítica das avaliações do local de trabalho feitas por outros ao invés de ele mesmo realizá-las.

Os profissionais do OHCC e da Rede aceitaram o seu papel não regulatório/governamental e não buscaram o reconhecimento legal do direito dos ambulatórios entrarem nos locais de trabalho. Como descrito acima, o OHCC tem procurado convencer os empregadores dos benefícios de permitir o acesso do ambulatório, assim como trabalhar através dos sindicatos para obter o acesso.

É difícil avaliar sistematicamente os resultados dos esforços do higienista relacionados aos pacientes porque não são documentados ou acompanhados de forma rotineira. A impressão que se tem é que uma proporção significativa das recomendações de controle de exposição do OHCC é atendida pelo menos em parte. Recomendações que só envolvem o paciente e não necessitam de cooperação, esforço e, idealmente, o conhecimento do empregador são as mais fáceis de implementar. Por exemplo, um trabalhador com lesões musculoesqueléticas pode ser capaz de avaliar a ergonomia de sua própria estação de trabalho utilizando os recursos fornecidos pelo OHCC e pode então fazer alterações simples com base em sua própria avaliação. No outro extremo do espectro, se as medidas preconizadas exigem um ato do empregador, em especial se consistem em ações que requerem despesas significativas, deslocamento de pessoal ou que podem gerar precedentes para outros trabalhadores, provavelmente serão combatidas ao invés de serem instituídas. Por exemplo, um paciente que trabalha com um produto de limpeza em uma escola desenvolveu asma severa. A recomendação feita foi substituir o produto por outro menos irritante. A escola se recusou, pois tinha um contrato com uma empresa fornecedora de determinada linha de produtos de limpeza que era utilizada na escola.

Vale mencionar que há relatos, bastante frequentes, em geral de pacientes, de que as recomendações feitas podem ter sido ignoradas nos seus casos, mas foram implementadas pelos empregadores mais tarde para outros trabalhadores. Nestas situações, os trabalhadores frequentemente fazem queixas formais para o seguro de compensação de trabalhadores e a empresa não deseja reconhecer sua responsabilidade legal pelos problemas de saúde. Paradoxalmente, ela vai contestar as reclamações dirigidas para a compensação de trabalhadores e nega ao trabalhador acidentado qualquer 
assistência, enquanto, ao mesmo tempo, faz algumas mudanças para proteger outros trabalhadores das mesmas condições perigosas. Enquanto isso, o trabalhador acidentado muitas vezes perde seu emprego porque se torna incapaz de continuar a trabalhar sem ajuda ou modificações no local de trabalho.

A agência que financia o OHCC, o Departamento de Saúde do estado de Nova York, exortou a rede de clínicas para usar a sua população de pacientes e quaisquer outros dados relevantes para focar esforços preventivos nas populações trabalhadoras sob risco. Para este fim, o OHCC tem de elaborar relatório anual de vigilância que resume seus dados clínicos e fornece a base para decisões sobre para onde direcionar futuros esforços.

Além disso, nas reuniões semanais de pacientes, buscam-se e identificam-se oportunidades de prevenção. Por exemplo, dois trabalhadores com asma foram atendidos, sendo que ambos trabalhavam em uma fábrica de máquinas com exposição a fluidos lubrificantes. Eles descreveram outros colegas em seu setor que apresentavam sintomas semelhantes. Neste caso, o sindicato e o empregador foram contatados, o problema foi descrito, juntamente com as implicações para os outros trabalhadores, e os serviços do OHCC foram oferecidos para mais investigação e remediação.

Na maioria dos casos, entretanto, oportunidades de prevenção são conquistadas de forma mais passiva, sob a forma de avaliações do local de trabalho, exames médicos ou oferta de treinamentos. Essas atividades são geradas por demandas, principalmente dos sindicatos, mas às vezes dos empregadores. Exames médicos periódicos são normalmente realizados para cumprir os regulamentos legais locais. Por exemplo, um empregador foi multado pela Occupational Safety and Health Administration ${ }^{8}$ (OSHA) por expor trabalhadores a níveis altos de sílica. O empregador chamou o OHCC para realização de exames para triagem de silicose, conforme exigido pela OSHA. Os exames mais comumente realizados são os de amianto, teste de adequação da proteção respiratória e exposição ao chumbo, todos exigidos pela OSHA.

Os exames às vezes são úteis para outros fins que não o seu objetivo principal. O sindicato dos telhadeiros utiliza o OHCC para exames de amianto e de adequação da proteção respiratória - conforme exigido pela OSHA - aos seus membros na área de Syracuse. No entanto, a maioria dos que trabalham com telhados raramente ou nunca usa máscara respiratória e está, pelo menos hoje em dia, exposta a uma quantidade mínima de amianto. Porém, os membros do sindicato são habitualmente expostos a solventes e outros produtos químicos, muitos sofrem de dor lombar devido à movimentação de materiais e outros movimentos que fazem. Além disso, muitos deles não têm acesso regular a médico ou cuidados médicos, portanto o exame de triagem é o único momento em que recebem cuidados de profissional de saúde. Muitas vezes, os membros do sindicato têm problemas de saúde não relacionados ao trabalho, mas que requerem atenção. Os mais comuns são pressão arterial alta e tabagismo. A triagem do amianto e o teste de efetividade da proteção respiratória levam os trabalhadores aos ambulatórios onde outros problemas de saúde podem ser resolvidos.

Um dos exames de triagem não obrigatórios oferecidos pelo OHCC em vários locais é voltado aos distúrbios osteomusculares e à ergonomia. Nesta triagem, três profissionais - médico, higienista/ergonomista e fisioterapeuta - encontram-se em três estações, onde recebem os participantes. Normalmente, os participantes apresentam alguns sintomas relativamente leves e muitas vezes não foram avaliados por nenhum profissional de saúde. Eles são beneficiados: pela opinião de médicos sobre seu diagnóstico e sobre quais seriam as próximas etapas de diagnóstico e tratamento apropriadas; pela análise do higienista/ergonomista sobre os riscos ergonômicos presentes nos seus locais de trabalho e como enfrentá-los; e pelas recomendações de fisioterapeutas acerca dos exercícios e tratamentos para aliviar os sintomas. Os exames são gratuitos e têm sido realizados em salões e organizações comunitárias. Além de oferecer conselho e, espera-se, proteção mais efetiva para pessoas em estágio de adoecimento menos avançado do que os pacientes do OHCC, estas sessões de triagem podem também revelar possibilidades para intervenções de saúde pública em locais de trabalho específicos. A triagem pode sugerir um padrão de lesão ou condições particularmente perigosas em uma situação de trabalho específica. Uma estratégia para abordar as questões pode então ser desenvolvida e implementada.

A educação e o treinamento oferecidos pelo OHCC tiveram vários grupos-alvo principais. Profissionais de saúde incluindo médicos, enfermeiros e assistentes sociais têm sido um foco contínuo. A localização do OHCC em um departamento de uma faculdade de medicina oferece oportunidades de contato com profissionais de saúde em formação e formados. A Medicina do Trabalho tem espaço regular, embora limitado, no currículo dos estudantes de Medicina, tanto nas residências em medicina interna, como na medicina de família e no currículo do curso de enfer-

${ }^{8}$ N.T.: Administração de Segurança e Saúde Ocupacional. Órgão federal que estabelece e faz cumprir as normas sobre saúde e segurança do trabalho no setor privado. 
magem. Relações com a escola local de serviço social também são de longa data. Através destas atividades, profissionais de saúde ganham habilidade na detecção da doença ocupacional e tornam-se melhor preparados para lidar com e encaminhar pacientes que apresentem problemas de saúde relacionados ao trabalho. Mais recentemente, uma ênfase especial para os médicos tem sido a compensação de trabalhadores, na tentativa de convencê-los da importância dos acidentes de trabalho para os seus pacientes e da necessidade da participação deles no sistema.

Sindicatos e trabalhadores formam o outro grupo principal que participa de atividades educacionais e de treinamento do OHCC. Assim como os exames médicos e as avaliações de higiene industrial, às vezes treinamentos são feitos para cumprir as normas da OSHA no que tange à eliminação do amianto e ao trabalho com resíduos perigosos. Outros cursos são ad hoc, em resposta a questões específicas levantadas por trabalhadores ou seus sindicatos. Por exemplo, há alguns anos, um sindicato que representa trabalhadores de uma empresa de produção de filtros descobriu que um material contendo sílica estava sendo utilizado na forma de pó para reduzir o atrito entre folhas de material transferidas na produção. $\mathrm{O}$ sindicato solicitou uma reunião com fins educativos na qual foram fornecidas informações técnicas acerca dos riscos à saúde da exposição à sílica. Também foi discutido o desenvolvimento de uma estratégia de ação para controlar as exposições.

Outro treinamento que merece ser mencionado como exemplo do envolvimento do OHCC nessas atividades é o programa de "orientadores" ${ }^{\text {da AFL- }}$ $-\mathrm{CIO}^{10}$ do estado de Nova York. Depois que a reforma da compensação de trabalhadores fez mudanças significativas na legislação do estado, a AFL-CIO desenvolveu um programa de treinamento de dois dias para formar membros do sindicato como "orientadores" da compensação de trabalhadores que poderiam ajudar os companheiros lesionados durante o processo. A intenção do treinamento foi fornecer-lhes experiência suficiente para que fossem capazes de oferecer conselhos básicos e encaminhamentos para recursos legais e do sindicato. Por vários anos o programa foi disseminado em todo o estado e oferecido repetidamente, tendo treinado milhares de trabalhadores. Os "orientadores" receberam certificado que comprovava sua participação no treinamento, que em geral durava cerca de 16 horas, mas que não lhes conferiu, entretanto, posição formal no sindicato. A maioria funcionava informalmente, oferecendo conselhos aos companheiros membros do sindicato que os procu- ravam. O OHCC participou regularmente dos treinamentos dos "orientadores" na sua região oferecendo uma perspectiva médica juntamente com outros participantes que tratavam das questões legais e relativas à relação entre trabalhadores e empresa.

\section{Atividades de pesquisa}

Como parte da sua obrigação em contribuir para a prevenção, o OHCC tem se envolvido em atividades de pesquisa. Grande parte tem sido baseada nos registros dos pacientes atendidos no serviço, na forma de relatos de casos clínicos ou de séries de casos. Por exemplo, o OHCC notificou a ocorrência de um grupo de casos de trabalhadores envenenados por chumbo empregados na indústria de cabos de telefone (LAX et al., 1996). Outro exemplo foi um estudo que avaliou as questões de saúde ambiental e respiratória devido à exposição a bioaerossóis e químicos em uma estação de tratamento de esgoto (LAX; SIWINSKI; MANETTI, 1999).

Outra pesquisa focou os aspectos da experiência do trabalhador lesionado, em particular, no sistema de compensação de trabalhadores. $\mathrm{O}$ trabalho feito pelo OHCC tem documentadas as dificuldades que trabalhadores lesionados enfrentam para ter acesso aos cuidados médicos, a natureza tendenciosa das "avaliações médicas independentes" (feitas por médicos contratados pelas companhias de seguro) em favor de empresas, e o grave trauma financeiro, social e psicológico sofrido por eles (LAX; MANETTI; KLEIN, 2004; LAX; KLEIN, 2008).

Outra vertente de pesquisa do OHCC aborda políticas ${ }^{11}$ com orientação histórica, em geral como tentativa de teorizar e desenvolver uma prática em relação a um problema específico. Esforços para capacitar trabalhadores e pacientes em torno de questões de saúde e segurança têm sido uma preocupação central desse trabalho (LAX, 2002).

\section{Relações com a comunidade}

\section{Conselho consultivo}

O conselho consultivo do OHCC tem variado de 20 a 30 membros e reúne-se quatro vezes por ano. Comitês ad hoc são formados de tempos em tempos para resolver problemas específicos que surgem. Os membros são recrutados normalmente pela equipe do OHCC, que identifica possíveis membros no decurso do seu trabalho ou por meio daqueles que já participam do conselho. Existe tentativa permanen-

\footnotetext{
${ }^{9}$ N.T.: Na versão original, o autor emprega a palavra navigator, ou seja, navegador, sem sentido para nós.

${ }^{10} \mathrm{~A}$ AFL-CIO do estado é a principal organização sindical que representa trabalhadores no âmbito estadual.

${ }^{11}$ N.T.: Na versão original, o autor emprega a palavra policy.
} 
te para manter a diversidade no conselho, o que permite a representação de todos os grupos interessados em segurança e saúde ocupacional. Os membros chamados são dos sindicatos, das empresas, dos serviços de saúde, das organizações comunitárias, dos trabalhadores lesionados e aposentados. O estatuto do conselho afirma que o ele será composto em maioria por representantes de pessoas diretamente afetadas por condições de trabalho perigosas. Na realidade, o conselho tem sido dominado por membros da comunidade e de trabalhadores.

A atividade geral do conselho tem variado ao longo do tempo. O OHCC e o conselho são em sua maioria dirigidos pela equipe, que elabora as pautas das reuniões do conselho e fornece a maior parte das informações nas reuniões. Logo no início, houve a necessidade de estabelecer com clareza a distinção entre um conselho diretivo e um consultivo, porque muitos dos membros do conselho inicial tinham experiência com conselhos diretivos e estavam prontos para se envolver com os detalhes de preparação de orçamentos e atividades do dia a dia do OHCC.

O conselho tem desempenhado papel importante em vários aspectos. Politicamente, membros do conselho e as organizações que representam têm defendido o OHCC em situações chave no âmbito estadual e dentro das suas instituições de origem. Por exemplo, a instituição na qual o OHCC é afiliada, a Universidade Médica do Norte do Estado da Universidade Estadual de Nova York, tentou retirar uma parte significativa do financiamento estatal designado para o OHCC e usá-lo para outros fins. Membros do conselho consultivo participaram de uma reunião com o presidente da universidade na qual enfatizaram o valor do OHCC e o impacto negativo do corte de orçamento proposto sobre os grupos aos quais ele serve. Como consequência, o corte foi reduzido significativamente. Os membros do conselho têm também acompanhado rotineiramente a equipe do OHCC para discutir com deputados estaduais da região a fim de obter apoio financeiro para o OHCC e a OHCN. Outra função do Conselho tem sido a de guiar o OHCC no desenvolvimento de serviços.

Os membros do conselho podem trazer questões que merecem ser tratadas pelo OHCC, podendo desempenhar papel importante na implementação das respostas. Discutem também com a equipe a fim de resolver problemas enfrentados pelo OHCC.

Eles se juntaram com funcionários do OHCC para falar publicamente sobre assuntos de saúde e segurança que surgiram na comunidade. Por exemplo, quando um grande shopping center estava sendo construído em área com resíduos perigosos, equipe e conselho exigiram da construtora a implementação de proteções eficazes para os trabalhadores que realizavam escavações e outros trabalhos no local e que apresentavam sintomas de problemas dermatológicos e respiratórios.

\section{Relações comunitárias}

Para que o OHCC faça seu trabalho de forma eficaz, tem sido importante para ele desenvolver relações com as organizações dos locais de trabalho e das comunidades envolvidas com questões de saúde e segurança. O OHCC tem continuamente feito esforços de articulação com os sindicatos em sua região, os quais resultaram em relações frutíferas e às vezes colaborações em projetos específicos. No mínimo, os sindicatos podem conscientizar seus membros sobre o OHCC de modo que seus serviços possam ser utilizados quando necessário. Outras atividades sindicais têm incluído fornecimento de informações e apoio técnico, desenvolvimento de serviços de triagem para os membros do sindicato, oferta de educação formal/treinamento e a realização de avaliações de saúde e de exposições no local de trabalho.

Outra relação importante estabelecida pelo OHCC é com o Council for Occupational Safety and Health ${ }^{12}$ (COSH), organização de trabalhadores que oferece apoio técnico e educação para trabalhadores sindicalizados e não sindicalizados e que visa à defesa das questões de saúde e segurança. Mais recentemente, dois centros de trabalhadores desenvolveram-se na região, com os quais o OHCC estabeleceu relações próximas. Os centros de trabalhadores foram desenvolvido para atender às necessidades de trabalhadores mais marginalizados, geralmente não sindicalizados. Outro foco importante desses centros é os direitos dos imigrantes. Para eles, o OHCC tem enfatizado, por meio de treinamento, os direitos de saúde e segurança dos trabalhadores, além de assistência técnica.

\section{Alcançando os não assistidos}

Embora o OHCC tenha feito um trabalho importante para cobrir o espectro das doenças ocupacionais na sua região, há muitos problemas que permanecem ocultos e sem ser abordados. Trabalhadores com salários baixos, em locais de trabalho não sindicalizados, são muitas vezes sujeitos a riscos graves, sem conhecimento de seus direitos em saúde e segurança ou informação sobre recursos em saúde e segurança. Ao longo dos últimos anos, o OHCC iniciou uma série de projetos para abordar algumas dessas necessidades. Esses esforços incluíram:

${ }^{12}$ N.T.: Conselho de Saúde e Segurança Ocupacional. 


\section{Trabalhadores migrantes}

O trabalho de migrantes é amplamente utilizado na agricultara na região do OHCC. Estes trabalhadores, em sua maioria, são do México e da Guatemala, muitos deles em situação irregular. Para aumentar o acesso à assistência médica, o Departamento de Saúde do condado $^{13}$ juntou forças com a Faculdade de Medicina da Universidade do Estado de Nova York (SUNY) para levar serviços médicos para as fazendas. Uma vez por semana, durante todo o período de safra, serviços médicos circulam entre fazendas diferentes. O OHCC participa nestas atividades, acrescentando o componente de saúde ocupacional que consiste em trabalho de diagnóstico, educação e fornecimento de equipamentos de proteção individual, como óculos de segurança. Questões de saúde ocupacional são comuns e incluem problemas lombares e outros problemas musculoesqueléticos, lesões oculares, dermatites, exposições a pesticidas e sintomas respiratórios. Como este programa é limitado a um município, o OHCC tem explorado e desenvolvido parcerias para levá-lo a outros grupos de trabalhadores migrantes na região.

\section{Tall Tower Project ${ }^{14}$}

Trabalhadores que constroem e mantêm torres de comunicação para telefones celulares, estações de rádio e televisão e outros fins estão submetidos a alto risco de morte e graves lesões por quedas, lesões causadas por trabalho em situações crônicas de má ergonomia, radiação não ionizante e uma variedade de outros perigos. Embora seja uma indústria relativamente pequena, assiste-se à tendência de crescimento enorme devido ao aumento do uso de telefones celulares. Muitas empresas do ramo são pequenas, contam exclusivamente com trabalhadores não sindicalizados e são espalhadas pelo território, o que dificulta o acesso a seus trabalhadores.

O OHCC tomou conhecimento desta ocupação por meio de um trabalhador de uma torre que foi ferido e se tornou um defensor da segurança e saúde dos trabalhadores no setor. O OHCC tentou facilitar seus esforços para construir uma rede de trabalhadores de torres com o objetivo de documentar e divulgar questões de saúde e segurança, oferecer aos trabalhadores informações sobre como se proteger, apoiar os trabalhadores lesionados e suas famílias, e construir uma agenda regulatória e legislativa para melhorar as condições de trabalho.

\section{Trabalhadores imigrantes}

O Norte do estado de Nova York tem sido alvo de um crescimento significativo de comunidades de imigrantes urbanos ao longo dos últimos vinte anos. São residentes permanentes que vieram de muitos lugares, com uma proporção significativa vinda de Cuba, do Sudão e da Bósnia. Muitos não têm fluência em inglês; outros, tampouco educação formal significativa e/ou experiência de trabalho. Consequentemente, muitas vezes possuem empregos de baixa qualificação, perigosos e com salários baixos. Em geral, o treinamento recebido é insuficiente e em inglês. Não recebem qualquer treinamento sobre direitos dos trabalhadores.

Para desempenhar um papel na resolução destas questões, o OHCC tem colaborado com os órgãos que prestam assistência aos imigrantes, como colocação em emprego, treinamento vocacional e instrução em inglês como segunda língua. A contribuição do OHCC tem sido o treinamento em direitos de saúde e segurança dos trabalhadores e em sistema de compensação de trabalhadores, além da defesa dos trabalhadores imigrantes que adoecem ou se acidentam no trabalho.

\section{Free clinics $^{15}$}

Como os Estados Unidos não têm um programa nacional de saúde e muitas pessoas carecem de seguro de saúde, existem centros que oferecem serviços gratuitos em várias áreas urbanas há muitos anos. Atendem pacientes desprovidos de seguro e recursos para pagar por cuidados médicos.

O OHCC tem documentado o fato de que a população servida pela free clinic de Syracuse enfrenta uma quantidade significativa de riscos relacionados com o trabalho e que uma proporção relativamente grande de seus pacientes sofreram acidentes de trabalho ou têm sintomas causados possivelmente por exposições no local de trabalho.

O OHCC desenvolve projeto para oferecer serviços nesta free clinic de forma regular e periódica. Pacientes das clínicas gratuitas enfrentam barreiras significativas para terem acesso aos OHCC de suas localidades. Ao levar sua equipe e seus serviços para a free clinic, o acesso será melhor para este grupo carente.

\footnotetext{
${ }^{13}$ N.T.: Em inglês, conty.

${ }^{14}$ N.T.: Em português, Projeto da Torre Alta.

${ }^{15}$ N.T.: Centros de saúde de serviços gratuitos.
} 


\section{Desafios}

No decurso do seu desenvolvimento, o OHCC tem enfrentado uma variedade de desafios. Alguns dos mais importantes, com relevância permanente, são descritos abaixo.

\section{Financiamento}

A verba que o $\mathrm{DOH}$ fornece corresponde à aproximadamente $75 \%$ do financiamento do OHCC, isto é, sem ela, o OHCC e a Rede de Clínicas não existiriam. Consequentemente, manter e aumentar o financiamento da Rede para lidar com despesas crescentes e prestação de serviços tornaram-se uma prioridade permanente. O financiamento depende da manutenção do apoio à Rede pela Assembleia Legislativa do estado e pelo governador. O movimento sindical organizado no estado de Nova York mantém influência política significativa. Com o apoio dos sindicatos e os esforços contínuos de comunicação com legisladores, a Rede foi capaz de manter o seu financiamento ao longo de 12 anos da vigência de um governo republicano conservador e dos últimos anos de uma crise fiscal devida à recessão.

Quanto tempo este apoio durará resta, todavia, como questão em aberto. Embora o atual governador seja do partido democrata, ele foi eleito em uma plataforma de austeridade e sem forte apoio dos sindicatos. No ano passado, o trabalho político da Rede e seus aliados foram suficientes para evitar um corte de 11\% no financiamento proposto pelo governador, posteriormente suspenso por ele. Com o enfraquecimento progressivo e a falta de conexão dos sindicatos com o atual governo, futuras tentativas de cortar o financiamento, no âmbito das medidas de austeridade gerais, não seriam surpreendentes. Neste contexto, a necessidade de apoio político amplo pode também diluir a capacidade da Rede de realizar sua missão de forma contundente. Em um esforço para obter favores, ou pelo menos não instigar a hostilidade da comunidade de empregadores, os serviços e a $\mathrm{DOH}$ podem agir com leveza e cautela excessivas, o que causará uma diminuição no seu impacto potencial na saúde pública.

\section{Atuando no seio de uma instituição maior}

O OHCC, ao mesmo tempo em que se beneficiou, foi prejudicada por sua relação com a SUNYUM. Benefícios tangíveis incluem apoio salarial para o diretor médico e desembolso antecipado anual para cobrir despesas do OHCC enquanto se espera pela chegada sempre tardia do financiamento. Menos tangível é o prestígio associado à base acadêmica, que pode melhorar a credibilidade e a eficácia do OHCC junto ao sistema de compensação dos trabalhadores e aos empregadores.
Por outro lado, o OHCC tem sido desafiado ao longo dos anos pela sua afiliação institucional, em particular sobre questões financeiras. Tanto a SUNY, quanto o Departamento de Medicina Familiar consideram o OHCC como fonte de receita e já tentaram utilizar fundos do OHCC para outros fins. Em geral, o apoio ao OHCC dentro da SUNY tem variado, embora, ao longo dos últimos seis anos, o interesse e o apoio institucional, também no âmbito do departamento, melhoraram muito devido a mudanças de direção.

\section{O “desaparecimento" da doença ocupacional}

A incidência e o espectro de doenças profissionais permanecem difíceis de serem determinadas com precisão nos Estados Unidos porque não existe nenhum mecanismo de notificação nacional. Os médicos não são treinados para reconhecer doenças profissionais e substâncias continuam a ser introduzidas nos locais de trabalho sem o conhecimento do seu impacto sobre a saúde. O reconhecimento da doença ocupacional sempre dependeu da participação ativa dos próprios trabalhadores, que trazem suas observações e suspeitas. A voz do trabalhador enfraqueceu substancialmente em muitos aspectos, o que contribuiu para um "desaparecimento" de doença ocupacional.

Em tempos econômicos difíceis, trabalhadores se sentem privilegiados por terem emprego, estando muito mais dispostos a barganhar preocupações com a saúde por uma suposta segurança no emprego. Além disso, a filiação sindical continua em declínio, o que deixa mais trabalhadores sem apoio quando questões de saúde no local de trabalho são levantadas. Mesmo os sindicatos existentes perderam muito de seu poder e têm receio de agir de forma agressiva em busca dos objetivos de saúde e segurança se esses esforços são percebidos como ameaça ao emprego.

Menos demonstrável, mas não menos importante, têm sido os esforços contínuos para reduzir a voz do trabalhador em saúde ocupacional. A compensação de trabalhadores é uma arena onde isto tem sido particularmente evidente. Do ponto de vista das companhias de seguro, o mundo é dividido em dados subjetivos e objetivos. Os dados subjetivos, de acordo com a definição das companhias, incluem sintomas dos trabalhadores, histórico de exposição do trabalhador e até mesmo, cada vez mais, muitos resultados de exames físicos. Os dados subjetivos, por definição, carecem de credibilidade. Os únicos dados válidos e confiáveis a seus olhos são "objetivos" e incluem amostras de ar, resultados de testes de diagnósticos e dados de exposição fornecidos pelo empregador. Ao estreitar os parâmetros "aceitáveis" dos dados desses esforços, reduz-se a possibilidade de identificação da doença ocupacional. 
Finalmente, a natureza do trabalho no estado de Nova York mudou de forma radical nos últimos trinta anos. A economia dependente, sobretudo, do tradicional setor industrial tornou-se uma economia dominada por serviços, que inclui saúde, educação e serviços de alimentação, e em menor escala, muitas vezes, por indústrias não sindicalizadas. Isso mudou a natureza dos perigos que os trabalhadores encontram e os contextos em que os perigos "tradicionais" são encontrados. Como consequência, trabalhadores com exposição a produtos químicos aparecem mais esporadicamente no ambulatório, trabalhadores com lesões lombares e problemas musculoesqueléticos sofridos em atividades no setor de serviços são vistos por ortopedistas e outros especialistas, trabalhadores com problemas de saúde relacionados à "nova economia", como estresse, qualidade do ar no local de trabalho e assédio moral no trabalho, podem procurar cuidados de saúde sem que a conexão com o local de trabalho seja sequer reconhecida.

\section{Mudanças na compensação dos trabalhadores}

O estado de Nova York aprovou uma importante reforma da compensação de trabalhadores em 2007. Entre os elementos da reforma estavam adaptações dos formulários que os médicos são obrigados a usar para notificar o Conselho de Compensação dos Trabalhadores, assim como novas diretrizes para tratamento que os médicos são obrigados a seguir. Antes dessas reformas, já havia número significativo de médicos em quase todas as especialidades que não participavam da compensação de trabalhadores. Depois das reformas, uma onda sucessiva de médicos saiu da compensação de trabalhadores.

Os médicos sempre acharam os requisitos de notificação da compensação de trabalhadores onerosos. Os novos formulários foram vistos como um fardo adicional e alguns médicos não estavam dispostos a gastar mais tempo fazendo trabalho burocrático não remunerado. As diretrizes de tratamento médico foram implementadas aproximadamente dois anos mais tarde do que os formulários e dizem respeito às lesões do pescoço, lombares, nos ombros e joelhos. Um número ainda maior de médicos mostrou a sua oposição, deixando o sistema devido ao fardo adicional de aprender e de mudar suas práticas para atender às complexas exigências das diretrizes.

Como consequência dessas mudanças, muitos pacientes que receberam previamente tratamento para sua lesão no trabalho em um consultório médico comunitário se encontraram sem atendimento. Um número significativo encontrou seu caminho no OHCC. Isto colocou um desafio significativo para os recursos do OHCC.

O OHCC tem lutado para atender às necessidades desses pacientes, ao mesmo tempo em que se man- tém disponível para servir os pacientes para quem a rede de OHCCs foi originalmente criada. Como consequência, parte significativa da prática do OHCC mudou do diagnóstico da doença profissional para o tratamento de trabalhadores com lesões crônicas.

\section{Mantendo recursos para prevenção e saúde pública}

Uma última questão que tem sido colocada como desafio desde o início da rede de OHCC é proteger o tempo da equipe dedicado à prevenção primária e secundária da doença ocupacional. O consumo de tempo é considerável para avaliar pacientes e lidar com a miríade de questões levantadas. As necessidades dos pacientes frequentemente tem que ser atendidas no curto prazo e não podem ser adiadas.

O DOH tem agravado este problema pela falta de clareza e direção sobre quanto valor deve ser colocado no atendimento a cada paciente versus as atividades preventivas. O OHCC é estimulado a se engajar na prevenção, mas as estatísticas que são coletadas pelo $\mathrm{DOH}$ e as discussões por ele conduzidas enfatizam o atendimento ao paciente e sugerem que as decisões sobre financiamento são baseadas principalmente no desempenho do OHCC nessa área.

\section{Conclusão: onde estivemos e para onde vamos}

A Rede de Centros de Saúde Ocupacional do estado de Nova York, da qual o OHCC de Syracuse faz parte, continua a ser a única rede deste tipo nos Estados Unidos. A utilização das receitas da compensação de trabalhadores para financiar clínicas a fim de diagnosticar, tratar e prevenir a doença profissional continua a ser um passo ousado para preencher um grande buraco no sistema de atenção médica e saúde pública. O financiamento público não só sustenta os ambulatórios, mas também os torna financeiramente independentes dos empregadores e, consequentemente, pelo menos em tese, sem restrições em salientar as condições de trabalho perigosas que estão tornando os trabalhadores doentes (LAX, 1992).

O grande sucesso do OHCC é o impacto concreto que teve sobre cerca de 6.000 trabalhadores/pacientes que passaram por suas portas em busca de cuidados médicos. O ambulatório prestou assistência médica, defendeu a causa dos trabalhadores lesionados em seus locais de trabalho, ajudou trabalhadores lesionados a obterem e manterem recursos provenientes do Sistema de Compensação e outros benefícios, também ajudou os trabalhadores lesionados e suas famílias a lidarem com suas doenças e lesões.

De modo mais geral e conciso, embora não menos importante, o OHCC demonstrou os profundos 
impactos psicológicos, sociais, financeiros e físicos que uma lesão ou doença no local de trabalho normalmente ocasiona. O poder da demonstração não deve ser subestimado em um contexto que paulatinamente procura silenciar a voz dos trabalhadores feridos, relegá-los ou relegá-las para alguma esquina esquecida, caracterizá-los ou caracterizá-las como membro "não produtivo" da sociedade ou, pior, como uma fraude que busca obter algo de graça. A manutenção de um espaço para a voz dos trabalhadores ser ouvida é talvez o maior sucesso do OHCC.

\section{Referências}

LANDRIGAN, P. J.; MARKOWITZ, S. B. Occupational Disease in New York State: proposal for a statewide network of occupational disease diagnosis and prevention centers. Report to the New York State Legislature. New York: Mount Sinai School of Medicine of the City University of New York, February, 1987.

LAX, M. B. The Occupational Health Clinical Center Network in New York State: achievements, prospects, and constraints. New Solutions - A Journal of Environmental and Occupational Health Policy, v. 3, n. 1, p. 41-54, 1992.

. Occupational medicine: toward a worker/ patient empowerment approach to occupational illness. International Journal of Health Services, v. 32, n. 3, p. 515-549, 2002.

LAX, M. B. et al. Lead poisoning and telephone cable strippers: a new setting for an old problem. American Journal of Industrial Medicine, v. 30, n. 3, p. 351-354, 1996.

LAX, M. B.; KLEIN, R. More than meets the eye: social, economic, and emotional impacts of workrelated injury and illness. New Solutions - A Journal of Environmental and Occupational Health Policy, v. 18, n. 3, p. 343-360, 2008.
Enquanto o OHCC segue seu curso depois do seu $25^{\circ}$ aniversário, continuará a ser desafiado por restrições de financiamento e pela agenda de austeridade do Estado. Ao considerar que o OHCC e a Rede possam estar à altura deste desafio, o ambulatório vai avançar com grande e contínua ênfase no desenvolvimento de abordagens eficazes para responder às necessidades de saúde e segurança de trabalhadores carentes, marginalizados e vulneráveis, continuando a atender as necessidades clínicas dos que adoecem por causa do seu trabalho.

LAX, M. B.; MANETTI, F. M.; KLEIN, R. Medical evaluation of work-related illness: evaluations by a treating occupational medicine specialist and by independent medical examiners compared. International Journal of Occupational and Environmental Health, v. 10, n. 1, p. 1-12, 2004.

LAX, M. B.; SIWINSKI, G.; MANETTI, F. An assessment of exposure and respiratory health among sewage treatment pressroom workers. In: INTERNATIONAL CONFERENCE ON BIOAEROSOLS, FUNGI, AND MYCOTOXINS: HEALTH EFFECTS, ASSESSMENT, PREVENTION AND CONTROL, 3., 1999, New York. Proceedings... New York: Eastern New York Occupational and Environmental Health Center, 1999. p. 125-130.

OCCUPATIONAL HEALTH CLINICAL CENTERS. Annual Report. Submitted to the New York State Department of Health. New York, NY: Mount Sinai University School of Medicine, April 2010.

TUMINARO, D. Organizing for a statewide network of occupational disease diagnostic centers. New Solutions - A Journal of Environmental and Occupational Health Policy, v. 1, n. 1, p. 18-19, 1990. 